\title{
THE TRAIT THEORY OF LEADERSHIP AND THE EIGHT-FOLD NOBLE PATH AS BUDDHIST LEADERSHIP PARADIGM: A STARK SCRUTINY
}

Bastola Dipak $^{2^{*}}$

\section{Abstract}

This paper titled, The Trait Theory of Leadership and The Eight-Fold Noble Path as Buddhist Leadership Paradigm: A Stark Scrutiny, strives to explore an affinity between the trait theory and the eight-fold noble path, to scrutinize the theoretical and practical implication of the integrated approach of both from the Nepalese perspective, and to expedite potential paradigm shift to enhance the leadership competencies of the 21st century. It is a conceptual paper. The secondary data has been profoundly analyzed to accumulate required facts, details, and information through comprehensive literature reviews. In conclusion, there is an obvious and precise affinity between both conceptions to propose an integrated paradigm transmutation for the enhancement of leadership competencies of the 21st century. From the Nepalese perspective, the empirical implication and application of the integrated leadership approach with the amalgamation of both i.e. the trait theory and the eight-fold noble path are seen inevitable as well as undeniable.

\section{Keywords:}

Meditative Traits, Moral Traits, The Eight-Fold Noble Path, The Trait Theory of Leadership, Wisdom Traits,

\section{Introduction}

The intensive accessibility of information has accelerated philosophical concepts from all corners of the world from their historical habitats into global communities. Buddhism, as the foundational philosophy of this paper, for instance, has helped to contribute to advances in the psychology chronicles of both western and non-western thinkers in the past, and continues to do so in contemporary times (Hansen, 2007; Riner, 2010; Fulton, 2014). Many reasons could be brought forward for this advancement, and one of the most significant ones is an integrated leadership through an immaculate blending of contemporary leadership paradigm with the spiritual leadership of Buddhist philosophy. Today's employees are looking for leaders that believe in altruism and raise their minds and actions beyond self-interest (Kemavuthanon \& Duberley, 2009).

Buddhist teaching is closely related to this view, as it delineates that we attain life's objectives in $2{ }^{*}$ Mr. Bastola is Associated with Tribhuvan University and Tourism Sector of Nepal can be corresponded at dipak532399@gmail.com 
three tiers: personal advancement (Attatha), the advancement of others (Parattha), and reciprocal advancement (Ubhayattha) (Kemavuthanon \& Duberley, 2009). So, could Buddhism, when anticipated as a psychological practice, lead to an integrated leadership within contemporary leaders? To find that out, this paper links an ancient Buddhist cluster of eight cardinal traits as the eight-fold noble path to contemporary needs for leaders' practices, thus presenting a useful roadmap to those who might consider this a viable paradigm for their leadership performance from here onward after assessing the semblance and implication of contemporary leadership i.e. trait theory of leadership and eight-fold noble path as Buddhist leadership in Nepalese context and expediting potential paradigm transmutation of trait approach from Buddhism perspective to enhance the leadership competencies of 21st century. Since substantial numbers of Buddhists have been living in a country like Nepal for so many years with long legacy, the leadership approach with an immaculate blend of Buddhism spirituality is the need of the hour to magnify the leadership competencies of the $21^{\text {st }}$ century. Though Nepalese societies are significantly diverged in terms of religions, cultures, traditions, social customs, and values, interestingly, people have an incredible inclination towards religious, cultural, traditional, and social harmony and coexistence. Thus, an empirical implication of Buddhism-based leadership approach especially in a country like Nepal is enormously high. Social welfare of Nepalese community is based on Buddhist's philosophy (Badal, 2017).

\section{Objective and method}

This paper first unfolds a crispy philosophy of Buddhism followed by an exploration of the trait approach of leadership, an analogical penetration between Buddhist leadership as an eight-fold noble path and trait theory of leadership, and subsequent discussion with conclusion respectively. It is a conceptual paper. The secondary data has been profoundly analyzed to accumulate required facts, details, and information through comprehensive literature reviews.

\section{Analysis}

\section{Buddhism Philosophy in Brief}

Most of us know the life and basic teachings of Gautama Buddha since our childhood days. He was born in a royal family at Kapilavastu, on the foot-hills of Himalaya, in the 6th century BC. The sights of disease, old age, and death impressed the young prince with the idea that the world was full of suffering and he renounced the world early in life. As an ascetic, he was restless in search of the real source of all sufferings and the path or means of cessation from these sufferings. He sought answers to his questions from many learned scholars and religious teachers of his time, but nothing 
satisfied him. He practiced great austerities, went through intense meditations with an iron will and a mind free from all disturbing thoughts and passions. He endeavored to unravel the mystery of the world's miseries. Finally, his mission was fulfilled and Prince Siddhartha became Buddha or "Enlightened". The message of his enlightenment laid the foundation of both the Buddhist religion and philosophy. Like all great teachers of ancient times, Buddha taught by conversation and our knowledge of Buddha's teachings depends on the "Tripitakas" or the three "baskets" of teachings of Gautama Buddha. The third part or "basket" is known as the Abhidhamma in Pali; and Abhidharma in Sanskrit. Abhidhamma Pitaka articulates simultaneously a philosophy, psychology, and ethics, all integrated into the framework of a program for liberation (Marques, 2015).

The Buddha's insights have been formalized in various "vehicles" or "schools," were passed on through the centuries, and have since spread worldwide. The most commonly known schools, sometimes referred to as "vehicles," are Theravada, also known as the older smaller vehicle, and Mahayana, also known as the larger vehicle. Even though they have some important philosophical differences, the two schools share several critical foundational insights and teachings such as suffering, impermanence, no-self, karma, nirvana, dependent origination, mindfulness, and the Four Noble Truths and the Noble Eightfold Path (Marques, 2015). Buddhism presents a selected worldview and way of living that results in personal understanding, happiness, and a wholesome development (Johansen \& Gopalakrishna,2006). It is often described as an ethical, ethical, valuebased, scientific, educational system that serves the aim of enabling its observers to ascertain things in their true nature, which can, in turn, help them get obviate suffering and attain happiness for themselves and lots of others. Buddha isn't to be worshipped as a god but revered as an awakened teacher (Johansen \& Gopalakrishna).

\section{The Four Noble Truths}

Buddha was primarily an ethical teacher and reformer, not a metaphysician. He disliked metaphysical discussions devoid of practical utility. Instead of discussing metaphysical questions, which are ethically useless and intellectually uncertain, Buddha always tried to enlighten persons on the foremost important questions of sorrow, its origin, its cessation, and therefore the path resulting in its cessation. The answers to those four questions constitute the essence of the Buddha's enlightenment. These have come to be referred to as four noble truths. They are:

1. Life is filled with suffering (Duhkha),

2. There's an explanation for this suffering (Duhkha-samudaya), 
3. It's possible to prevent suffering (Duhkha-nirodha),

4. There's how to extinguish suffering (Duhkha-nirodha-marga).

(Chatterjee, 1998; Rhys, 2003).

The primary noble truth is a life filled with suffering. The very essential conditions of life seemed to be fraught with suffering-birth, old age, disease, death, sorrow, grief, wish, despair, in short, all that's born of attachment, is suffering. The second noble truth is that there's an explanation for this suffering. Suffering is due to attachment. Attachment is one translation of the word Trishna, which can also be translated as thirst, desire, lust, craving, or clinging. Another aspect of attachment is dvesha, which means avoidance or hatred. The third aspect of attachment is avidya, meaning ignorance. The third noble truth about suffering is that suffering can be extinguished. Nirvana is the state of being wherein all clinging, and so all suffering can be eliminated here, in this very life. Buddha pointed out that work without attachment, hatred, and infatuation (rāga, dveșa, moha) does not cause bondage. The fourth noble truth about suffering is that there's a path (marga)which Buddha followed et al. can similarly follow-to reach to a state free from misery. He called it the Eightfold Path to liberation. Eightfold Path (astangika-marga): this provides, during a nutshell, the essentials of 'Buddha Ethics'.

\section{Eightfold Path}

This path is hospitable all, monks also as laymen, the primary two segments of the trail are mentioned as Prajña, meaning wisdom

1. Right views-understanding the Four Noble Truths, especially the character of all things as imperfect, impermanent, and insubstantial and our self-inflicted suffering as founded in clinging, hate, and ignorance.

2. Right resolve/aspiration-having truth desire/determination to free oneself from attachment (desire), hatefulness (anger), and ignorance. The next three segments of the path provide more detailed guidance in the form of moral precepts or conduct, called 'sila':

3. Right Speech-Abstaining from lying, gossiping, and hurtful speech generally. Speech is often our ignorance made manifest and is the most common way in which we harm others.

4. Right action/Conduct-Right conduct includes the 'Pancha-Sila', the five vows for desisting from killing, stealing, sensuality, lying, and intoxication. 
5. Right Livelihood-Making one's living in an honest, non-hurtful way. The last three segments of the trail are those Buddhism is most famous for, and concern samadhi or meditation. Despite the popular conception, without wisdom and morality, meditation is worthless, and may even be dangerous.

6. Right effort - Taking control of your mind and the contents thereof, effort to develop good mental habits. When bad thoughts and impulses arise, they should be abandoned. This is done by watching the thought without attachment, recognizing it for what it is, and letting it dissipate. Good thoughts and impulses, on the opposite hand, should be nurtured and enacted.

7. Right mindfulness - Mindfulness refers to a sort of meditation (vipassana) involving an acceptance of thoughts and perceptions, a "bare attention" to those events without attachment. This mindfulness is to be extended to existence besides. It becomes the way of developing a fuller, richer awareness of life.

8. Right concentration - One who has successfully guided his life within the lifetime of the last seven rules and thereby freed himself from all passions and evil thoughts is appropriate to enter into deeper stages of concentration that delicately take him to the goal of his long and arduous journey - cessation of suffering (Premanode, 2009).

Since the trait theory of leadership has equivalent and compatible constituents of Buddhist leadership as an Eight-fold noble path, the former paradigm has been substantially applied more in a secular manner which entails the essentials of the Eight-fold noble path as leadership guidance have also been profoundly employed not in a spiritual manner. So the contemplation regarding the practical and theoretical implication of Trait Theory as the Eight-Fold noble path is out of question i.e. through met theoretical examination, it is obvious to have the high implication of Trait Theory as Eightfold noble path not only to leaders but also to non-leaders to cultivate the required amount of virtue to propel professional as well as spiritual momentum to amplify leadership competencies. Especially in a country like Nepal, the birthplace of Buddha, where approximately $10 \%$ of the total population are Buddhist, live and have a long legacy, has an enormous significance to have a well-integrated leadership approach compiling contemporary and Buddhism based leadership thoughts. Conceptual exploration through works of the literature suggests that even though Traits Leadership paradigm amalgamates the ingredients of the Eight-fold noble path as requisite traits of leaders, the behavioral as well as practical void or vacuum has been witnessed from leaders' perspective to literally accommodate those traits i.e. wisdom traits, moral traits, and meditative traits to justify to Eight-fold Noble path as Buddhist leadership paradigm. So to 
counteract to the potential spiritual as well as non-spiritual challenges of future leadership and to amplify the competencies of 21st-century leadership, practical, realistic, empirical, and spiritual integration of the Eight-fold Noble Path as Buddhist leadership paradigm and Trait Leadership Theory is inevitable and undeniable especially in a country like Nepal. The need of the hour is to expedite and develop morality, empathy, virtue, humility, modesty oriented leadership paradigm which becomes reality with the potential transmuted phenomenon in Trait Theory of leadership by blending cardinals of the Eight-fold noble path of Buddhism philosophy.

\section{The Trait Approach to Leadership}

The trait theory of leadership as a good man theory of leadership states that some people are born with the required attributes to be great leaders. Alexander the good, full general, Joan of Arc, Catherine the good, Napoleon, and spiritual leader are cited as naturally great leaders, born with a collection of private qualities that made them effective leaders. Even today, the belief that truly great leaders are born is common. For example, Kenneth Labich, writer for Fortune magazine, commented that "the best leaders seem to possess a God-given spark."

Trait theory is that the approach to check an individual's personality that identifies \& measures the degree thereto convinced personality traits; fairly often recurring patterns of thoughts and behavior of any human, like anxiousness, shyness, pessimist thought, optimist thought, openness to new things that exist from individual to individual. Trait theorists believe personality will be understood by positing that everyone people have certain traits or characteristic ways of behaving (Boundless, 2015). The list of famous trait theories is: Gordon Allport's 4000 traits theory (18971967), Raymond Cattell's Sixteen Personality Factor Questionnaire (1905-1998), Hans Eysenck's Three Dimensions of Personality (1916-1997), and The Five-Factor Theory of Personality (The Big Five ( OCEAN). The brief description of the theories is as below:

Gordon Allport's 4000 traits theory

Gordon Allport was one in all the pioneers of formal personality psychology and is taken into account as the first modern trait theorist who had adopted the trait approach against the sort approach for the outline of personalities. As per him, the traits are the essential units of personality and each person develops a novel set of organized tendencies called traits. In 1936, he found that one English language dictionary alone contained quite 4000 words which describe the human personality traits. Allport categorized the traits into three levels: Cardinal Traits are traits that rule or control an individual's whole life, often to the purpose that the person becomes known specifically for these traits like Ebenezer Scrooge's greed or Mother Theresa's altruism. They 
stand at the highest of the hierarchy and are collectively called the individual's master control. Central Traits are the overall characteristics found in varying degrees and form the fundamental foundations of personality in everyone. Terms like intelligent, shy, honest \& anxious are samples of central traits. Secondary Traits are the traits that are sometimes associated with attitudes or preferences and infrequently appear only in certain situations or under specific circumstances.

Raymond Cattell's Sixteen Personality Factor Questionnaire (1905-1998)

Trait theorist Raymond Cattell, the research assistant of Charles Spearman reduced the number of main personality traits from Allport's initial list of over 4,000 all the way down to 171, mostly by eliminating uncommon traits and grouping common characteristics. After intensive research and observation, Cattell synthesized sixteen dimensions of a collection of human personality traits like abstractedness, warmth, emotional stability, apprehension, openness to varying, liveliness, perfectionism, privatives, rule consciousness, intelligence, tension, social boldness, sensitivity, self-reliance, vigilance, dominance.

Hans Eysenck's Three Dimensions of Personality Traits

Hans Eysenck continued the research on personality traits and had narrowed the list of characteristics to 3 main areas.

1. Introversion/Extraversion: Introversion involves directing attention to inner experiences, while extraversion relates to focusing attention outward on other people and the environment. So, a person high in introversion might be quiet and reserved, while an individual high in extraversion might be sociable and outgoing.

2. Neuroticism/Emotional Stability: As per the Eysenck's trait theory, this dimension is related to moodiness vs. even-temperedness. Neuroticism is an individual's tendency for becoming distressed or emotional while stability is the tendency to remain emotionally constant.

3. Psychoticism: Later on Eysenck studied about individuals suffering from various mental illnesses, which ultimately let him add another personality dimension called psychoticism in his trait theory. Individuals, high on the mentioned trait usually tend to possess difficulty in coping with reality and maybe antisocial, non-empathetic, hostile \& manipulative.

The Five-Factor Theory of Personality (The Big Five / OCEAN)

In a background of Cattell's theory that was too complex and Eysenck's was too limited in scope, 
the five-factor theory emerged to describe the basic traits that serve as the building blocks of personality. Evidence of this theory has been growing over the past 50 years, beginning with the research of D. W. Fiske (1949) and later expanded upon by other researchers including Norman (1967), Smith (1967), Goldberg (1981), and McCrae \& Costa (1987).

"Big Five" broad five categories of personality traits dimensions are:

1. The dimension called Extraversion includes certain characteristics like excitability, talkativeness, sociability, assertiveness $\&$ high amounts of emotional expressiveness.

2. The dimension called Agreeableness includes certain attributes like trust, altruism, kindness, affection, and lots of other pro social behaviors.

3. The dimension called Conscientiousness includes high levels of thoughtfulness, with good impulse control and goal-directed behaviors like high in conscientiousness usually tend to be organized \& mindful of details.

4. The Dimension called Neuroticism tends to experience emotional instability, anxiety, moodiness, irritability, and sadness.

5. The Dimension called Openness features characteristics like imagination \& insight. Those high during this trait tend to possess a broader range of interests.

Trait theories of trait approaches are one of the systematic attempts which study leadership concept since the early 20th century up to the late 1940s. It is the only trait approach that advocates about the concept of leadership that it is innate \& linked to personal qualities. Despite lots of weaknesses in the popular trait theories, they provide worthy useful and valuable information about the concepts of leaders and leadership which will further be proved important not only on the individual level but also on the organizational level. Individuals especially leaders can analyze their own specific set of traits through various popular tests \& questionnaires and let themselves aware and understand their strengths, weaknesses, and status as per the previews of their colleagues and management. In this way, managers or leaders can assess where they actually stand in their organizations and how they can strengthen their position in their organization. Traits approaches and theories are the benchmarks for the personalities who want to have become a successful leader (Northouse, 2007). In recent times, the trait approach has created a sensation within the concept of leadership and leader thus many renowned researchers are taking interest during this topic and tries to clarify how traits influence leadership and leaders. As per North house theory, trait approaches started applying emphasis on identifying the unique set of qualities of a 
great person which is shifting their focus on the impact of different situations on leadership. In the most up-to-date era, that emphasis has turned back or shifted back to reemphasize the many roles of traits within the concept of effective leadership.

\section{An analogical penetration: Buddhist Leadership as Eight-fold Noble path and Trait Leadership}

Leadership approaches and actions tend to be significantly different going through tangible as well as intangible congenital as well as acquired individual characteristics, features, attributes, and behaviors. The total sum of those individual facets is termed as Traits. The effectiveness and efficiency of leaders somehow rely on those traits and well implementation of those distinguished features which vary incredibly leaders to leaders. Different theories of Trait leadership also have forwarded innumerable traits to become a successful leader but those traits actually fall or revolve under the consideration of the Eight-fold noble path of Buddhism. The Eight-fold noble path of Buddhism as leadership traits has become an inevitable essential or requisite to enhance global leadership competencies of the 21st century and an integrated leadership model. Those essentials are explained as eight-fold noble path as leadership traits below:

\section{Wisdom Traits}

The right view engages to acquire a deeper understanding of the Four Noble Truths: the fact that we suffer; the reasons why we suffer; and the reality that we can choose to end our suffering. The right view can help us nurture good intentions and keep bad intentions quiescent (Thich, 1998). The right view has an incredible amount of prowess or ability to detect which of our mindsets are constructive and nourish those, to influences our perception, to discourage a negative view and perceive everything as an offense to the quality of life, to distinguish the positive lessons in each experience, to adjust limiting perspectives, and to influence our attitude. A leader with right view attribute under the wisdom trait has a tremendous capability of exploring constructive and destructive mindsets as well as perception, considering matters from a positive angle, segregating the positive lesson in each experience, adjusting perspectives in limitation, and influencing the attitude of followers with a propensity to nurture constructive mindset and to exterminate destructive mindsets.

Right intention is additionally designated as "right thinking," and pertains to mental focus. Maintaining the right intention isn't as easy because it could seem. Thich (1998) recommends four actions to refrain from losing right intention: 1) Ensuring proper understanding of what we see, read or hear, and contemplate, 2) Scrutinizing our actions,3) Inspecting our habits, and acknowledging, and 4) Nurturing an awakened mind to benefit others as much as possible. In Buddhism, this 
is referred to as "Bodhicitta." When we engage in Bodhicitta, we become filled to do well onto others and help them become happier beings. A leader with the right intention attribute under the wisdom traits ensures authentic comprehension of atmosphere or environment, evaluates actions to facilitate ethical behavior, examines favorable and unfavorable habits, and emerges as "Bodhichitta" to help or benefit others as much as possible.

\section{Morality Traits}

Right speech means telling the reality to the simplest of one's abilities, not creating divisiveness by telling different people various things, refraining from making cruel statements, and refraining from overstatements (Thich, 1998). A leader with right speech etiquette under the morality traits refrains from negative communication, practices mindfulness while disseminating information, resolves division and disharmony, fosters proactive listening as a constructive listener, and implements the right view and the right intention etiquettes of wisdom traits efficiently through the right communicative skill.

Right action starts, interestingly enough, with the discontinuation of action: the action of harming ourselves and others (Thich, 1998). This also means desisting from killing, stealing, lying, sensuality, and intoxication. Because temptation is all around us, it's not as easy because it could appear to interact in the right action. Killing, for instance, is a very broad topic. It also entails, for example, refraining from killing for pleasure (hunting). Having a leader with right action amenity under the morality traits encompasses a tremendous capability of refraining from wrong deeds such as killing, lying, sensuality, stealing, and intoxication which actually contribute significantly to cultivate virtues. Right action is in high need in our times, where wrong actions have led to warming, and therefore the loss and destruction of the many innocent lives within the environment, due to our inconsiderate, selfish behavior.

Right livelihood predominantly focuses on the nature of the work one does, and whether this is constructive or not. Thich (1998) suggests a number of the critical questions one could reflect on to make sure right livelihood, such as, a) whether one is producing, dealing in, or promoting weapons of any kind that are being employed to kill and destroy; b) whether one is engaging in practices where people are blatantly being taken advantage of, or c) whether one is involved within the production and/or promotion of destructive products like alcohol and medicines. The fact that a leader having the right livelihood means getting involved in ethical livelihood activities such as engaging in manufacturing those products or services which don't harm people, not getting involved to exploit people, and to get participated in socially accepted ventures. 


\section{Meditative Traits}

The right effort is usually also listed as "right diligence." While effort is mostly an admirable practice, it is directed to constructive or destructive activities. Right effort, like all other treads of the eightfold path, requires careful evaluation of our actions, thoughts, and intentions, to assess whether or not they are constructive or destructive activities. Right effort, like all other treads of the eightfold path, requires careful evaluation of our actions, thoughts, and intentions, to assess whether they are constructive. A leader is said to have right effort manner under meditative traits when he or she gets engaged in right diligence with constructive practices, in the mindful evaluation of our actions or deeds, thoughts, intentions, aspiration, initiation as to identify whether they are constructive or destructive, and subsequently in the empirical application of mind or psyche for right behavior.

In practicing mindfulness, we also practice all other facets of the eightfold path: right view, right intention, right speech, right action, right livelihood, right effort, and right concentration. once we are mindful, we see things that we usually consider granted: the grass, the trees, our partners, our colleagues, our pets, and that we realize fully that they're here now. The appreciation that's a part of mindfulness can alleviate the suffering of mindlessness, and encourage us to travel a step further, so we think about others, understand them better, and transform our own suffering and theirs into joy (Thich, 1998). A leader with right mindfulness character under the meditative traits has not only an enormous mental aptitude to understand the volatility of the surrounding, atmosphere, and environment in terms of having the required amount of information regarding what is going on in and around us but also to instigate or nourish mindfulness aptitude in others.

Right concentration is firmly intertwined with the opposite elements of the Noble Eightfold Path. Through the right concentration, we will specialize in what really matters. Right Concentration is oftentimes also observed as Right Meditation. Right mindfulness and concentration are both tools to sharpen the mind (Nouri, 2013), and might both be amplified through mindfulness meditation, also referred to as Vipassana. Through the right concentration, we will discover beautiful scenes and occurrences that accustomed escape our attention once we weren't focused. Right concentration can therefore lead us to greater happiness since we are more focused on what matters now. If we engage deep enough in the right concentration, we'll ultimately start realizing the impermanent nature of many of our cravings and learn to release them (Thich, 1998). Having this quality in a leader means to get focused in one particular phenomenon out of those phenomena which are acquired from right mindfulness as mindfulness attentively observes all that emerges, concentration includes a special target one object at a time (Nouri, 2013). A 
Focused, determined, and goal-centered leader is always a great asset to any organization to excel institutional competitiveness. Thus, the right concentration often drives leaders to be more concentrated, directed, and focused in their aims.

\section{Conclusion}

Leadership incompetence or failure not only takes a toll on an individual leader but also to an economy at all. Leadership has always been a debatable topic for centuries and the application of good leadership not only fosters the reputation of an individual leader, their thoughts, visions as well as the entities where they belong but also excels the humanity, social and moral virtues beyond expectation. In General, there are two eminent paradigms of leadership as one is briefly inclined to spirituality having incorporated fundamentals of Buddhism, Hinduism, Christianity, Islam, Jews, etc. and the other is more secular having assimilated essentials of productivity, profitability, efficiency, and effectiveness of individual, organizational and national priorities. The trait approach of leadership is one of the approaches that belongs to the latter paradigm whereas Buddhist leadership with a thorough application of the Eight-fold noble path is one of the approaches that belongs to the former paradigm. This paper, however, attempts to unpack or disclose innumerable dimensions of those two leadership paradigms i.e. Trait Theory of Leadership and Buddhist leadership as an Eight-fold noble path. Through the literature scrutiny, it is precise that leadership traits of Trait Theory have perfect semblance or affinity with all the constituents of the Buddhist philosophy of "Eight-fold noble Path" since those two philosophies are synonymous.

Trait Leadership Theory as a contemporary paradigm encompasses a myriad of leadership traits as soft and hard skills to get succeeded but it is apparent that those countless traits somehow revolve in and around the right view and right intention of wisdom traits, right speech, right action, and right livelihood of moral traits and finally right effort, right mindfulness, and right concentration or meditation of meditative traits. The empirical implication, as well as the application of the proposed integrated leadership paradigm, has a tremendous potentiality in a nation like Nepal where spirituality gets embodied everywhere, people are driven by multi-cultural influences, religious as well as cultural tolerance is incredibly high, people's upbringing is induced with the fundamental principles i.e. harmony and coexistence. So the time has come to remodel the trait theory of leadership from the Eight-Fold Path of Buddhism to strengthen leadership competencies of the 21st century. 


\section{References}

Allport, G.W. \& Odbert, H.S. (1936). Trait-names: A psycho-lexical study. Psychological Monographs, 47(211).

Badal, B. P. (2017). Social Welfare Model of Community Development. Nepalese Journal of Development and Community Studies, 14 (1\&2), 1-11.

Cattell, R.B. (1965). The scientific analysis of personality. Baltimore: Penguin Books.

Chatterjee S, Datta D. An Introduction to Indian Philosophy. 8th ed. Calcutta: Calcutta University Press; 1980. The Buddha philosophy.

Eysenck, H.J. (1992). Four ways five factors are not basic. Personality and Individual Differences, 13, 667-673.

Fiske, D. W. (1949). Consistency of the factorial structures of personality, ratings from different sources. Journal of Abnormal and Social Psychology.44. 329-344.

Fulton, P. (2014). Contributions and Challenges to Clinical Practice from Buddhist Psychology. Clinical Social Work Journal, 42(3), 208-217

Hansen, I. A. (2007). Buddhist Influences on the Idea of the Unconscious. Psychological Perspectives, 50(2), 181-197.

Johansen, B. C, \& Gopalakrishna, D. (2006). A Buddhist View of Adult Learning in the Workplace. Advances in Developing Human Resources, 8(3), 337-345.

Kemavuthanon, S. \& Duberley, J. (2009). A Buddhist View of Leadership: The Case of the OTOP Project. Leadership \& Organization Development Journal, 30(8), 737-758.

Marques, J. (2015). Business and Buddhism. New York: Routledge.

Northouse, P. G. (2007). Leadership: theory and practice. 4th ed. Thousand Oaks, CA: Sage Publications.

Nouri, D. (2013). What is the Eightfold Path? Secular Buddhist. Retrieved on April 12016 from http://secularbuddhism.org/2013/05/03/what-is-the-eightfold-path/

Passini, F. T., \& Norman (1966). A un' conception of personality, structure? Journal of Personality Social Psychology, pg: .44-49. 
Premanode, B. (2009). The great Thai leadership in early Buddhism, Institute of Bio-Medical Engineering, Imperial College, London.

Rhys Davids CA. (2003). Buddhist Manual of Psychological Ethics. Whitefish, MT: Kessinger Publishing; 2003.

Riner, P. S. (2010). East or West, the goal is the same: Buddhist psychology and its potential contributions to invitational education. Journal of Invitational Theory \& Practice, 1688104.

Thich, N. H. (1998). The heart of the Buddha's teaching: Transforming suffering into peace, joy, and liberation. New York: Broadway Books. 